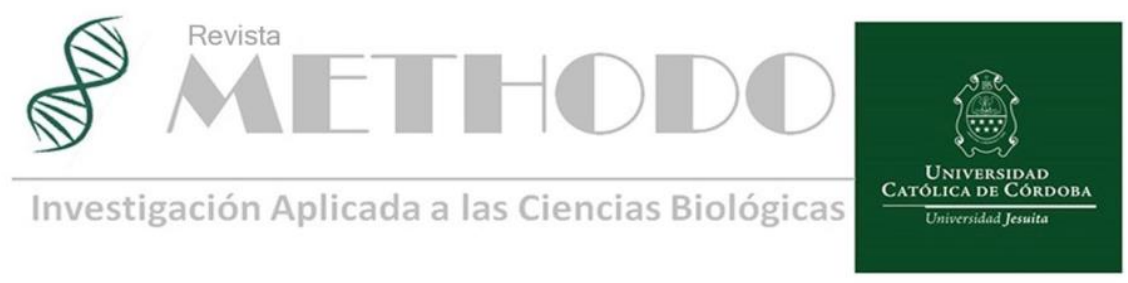

ARTICULO ORIGINAL Rev. Methodo 2021;6(3):127-131

https://doi.org/10.22529/me.2021.6(3)05

Recibido 12 Feb. 2020 | Aceptado 28 Abr. 2021 | Publicado 02 Jul. 2021

\title{
Enfermedad mano pie boca en adultos inmunocompetentes. Serie de casos
}

\section{Hand foot and mouth disease in immunocompetent patients. Case series}

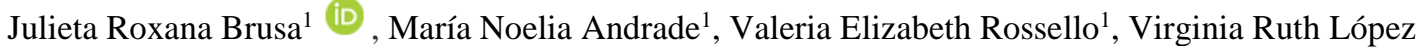 \\ Gamboa $^{1}$, María Susana Gómez Zanni ${ }^{1}$, Andrés Guidi ${ }^{2}$, Mariana Beatriz del Valle Papa ${ }^{1}$. \\ 1Universidad Católica de Córdoba, Facultad de Ciencias de la Salud, Clínica Universitaria Reina Fabiola, Servicio de Dermatología. \\ 2Universidad Católica de Córdoba, Facultad de Ciencias de la Salud, Clínica Universitaria Reina Fabiola, Servicio de Anatomía Patológica. \\ Correspondencia: Julieta Roxana Brusa. E-mail: julietarbrusa@gmail.com
}

\section{Resumen}

La Enfermedad mano pie boca es una patología exantemática viral muy contagiosa, de predominio en la edad pediátrica. Sus agentes etiológicos más frecuentes son los virus Coxsackie y Enterovirus. Se caracteriza clínicamente por la presencia de fiebre, erosiones en mucosa bucal y exantema máculo vesicular en regiones acrales. Generalmente se autolimita, pero puede presentar complicaciones severas con compromiso neurológico, pulmonar y cardíaco. Se han observado brotes mundiales, por lo que actualmente es considerada un problema de salud pública emergente, tanto en poblaciones pediátricas como adultos. Se presentan casos de pacientes adultos inmunocompetentes con transmisión intrafamiliar de Coxsackie B, sin complicaciones severas. Estos casos muestran la importancia de la prevención para evitar brotes epidémicos, además de destacar la presentación infrecuente en adultos inmunocompetentes.

Palabras clave: Enfermedad mano pie boca, Coxsackie B.

\begin{abstract}
Hand foot and mouth disease is a very contagious viral exanthematous disease, predominantly in the pediatric age. Its most frequent etiologic agents are Coxsackie virus and Enterovirus. It is clinically characterized by fever accompanied or followed by erosions in the oral cavity, and vesicular exanthema in acral regions, usually self-limited, but can present severe complications with neurological, pulmonary and cardiac compromise. Due to recent outbreaks, it is considered an emerging public health concern, not only in pediatric population, but also in adults. We present cases of immunocompetent adult patients with intrafamilial transmission of Coxsackie B, without severe complications. These cases highlight the need for preventive measures that may inhibit epidemic outbreaks, in addition to highlighting the infrequent presentation in immunocompetent adults.
\end{abstract}

Keywords: Hand foot mouth disease, Coxsackie B. 


\section{Introducción}

La Enfermedad mano pie boca (EMPB) se define como un exantema y enantema vesicular agudo, de curso autolimitado ${ }^{1}$. Es más frecuente en niños menores de 10 años y en adultos inmunocomprometidos, es producida por los virus Coxsackie A, B y Enterovirus ${ }^{2,3,4}$. La presentación en adultos inmunocompetentes es poco frecuente $^{2,3}$. Se presentan cinco casos clínicos de EMPB por Coxsackie $B$ en adultos inmunocompetentes.

\section{Casos Clínicos}

Caso I: Paciente masculino, de 26 años. Consultó por presentar episodios febriles y odinofagia de 5 días de evolución

Caso 2: Paciente femenino, de 23 años, hermana y conviviente del paciente del caso clínico 1. Consultó por presentar un episodio febril asociado a odinofagia, de 24 horas de evolución

Caso 3: Paciente femenino, 26 años. Consultó por síntomas respiratorios de vías aéreas altas. Afebril. $\mathrm{Su}$ hijo fue diagnosticado 4 meses previos a la consulta de EMPB.

Caso 4: Paciente femenino, de 39 años, presentó episodio febril y odinofagia de 4 días de evolución Caso 5: Paciente femenino, de 34 años, embarazo de veinte semanas de gestación. Cursó internación por prurito de difícil manejo, además presentó fiebre, odinofagia 6 días de evolución. Los pacientes no tenían antecedentes patológicos, posterior a los pródromos desarrollan dermatosis en palmas y plantas, en el caso 2;3;4 con compromiso en mucosa oral.

Al examen dermatológico los pacientes presentaron máculas y pápulas eritematoviolaceas en palmas y plantas que a las 72 horas evolucionaron con vesícula central de contenido seroso, distribuidas en espacios interdigitales, manos y pies (Figuras 1 y 2). Relataron dolor urente y prurito a nivel de las lesiones. El caso 2; 3 y 4 presentaron faringe congestiva con enantema en paladar, vesículas tensas de contenido claro en mucosa yugal, y cara lateral izquierda de lengua (Figura 3).

Ante la sospecha clínica de EMPB vs exantema viral, se solicitaron en todos los casos citológico completo, función renal, glucemia, hepatograma, proteína $\mathrm{C}$ reactiva, y pruebas serológicas para virus hepatitis B y C, VIH, VDRL, virus Herpes simple 1 y 2, Citomegalovirus, virus Epstein Barr, Parvovirus B19, Micoplasma pneumoniae, Chlamydia pneumoniae y Coxsackie. Los cuatro primeros pacientes tuvieron Inmunoglobulina (Ig) $\mathrm{M}$ positiva para Coxsackie $\mathrm{B}$, excepto el cuarto $\mathrm{y}$ quinto caso que presentaron $\mathrm{IgG}$ positiva para
Coxsackie B. Se descartó compromiso cardíaco, hepático y neurológico en los pacientes.

En el caso uno se realizó biopsia cutánea, cuyo estudio histopatológico informó piel con degeneración balonizante en la capa basal, disqueratinocitos aislados. En dermis se evidenció marcado edema, e infiltrado inflamatorio mixto, con presencia de melanófagos y hemosiderófagos ocasionales (Figura 4). En el resto de los casos no se realizó biopsia cutánea por la clínica característica, antecedente epidemiológico y serología compatible con el diagnóstico presuntivo.

En base a la clínica y los estudios solicitados se arribó al diagnóstico EMPB, por lo que se indicó tratamiento sintomático con desloratadina $5 \mathrm{mg}$ y betametasona $0.6 \mathrm{mg}$ vía oral diario durante 15 días, reposo y medidas generales. Se informó acerca del correcto lavado de manos, cuidados de fómites, aislamiento relativo y curas planas de las lesiones. Los pacientes presentaron buena evolución con descamación en palmas y plantas y mejoría clínica a los 15 días del inicio de los síntomas.

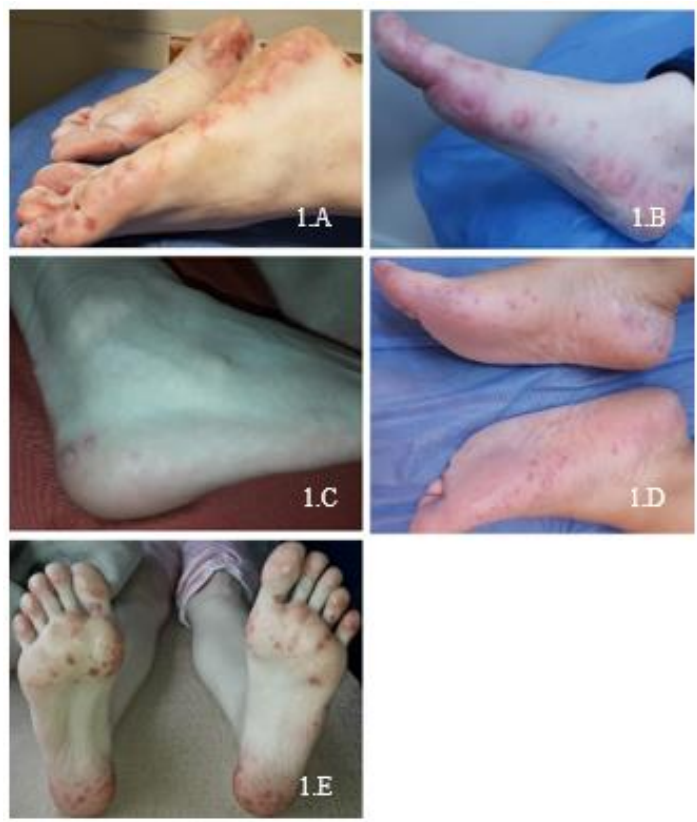

Figura 1. casos clínicos 1 al 5 (A-B-C-D-E): máculas circulares eritematopurpúricas, vesículas contenido seroso con halo eritematoso en plantas de ambos pies, algunas se extienden a dorso. 

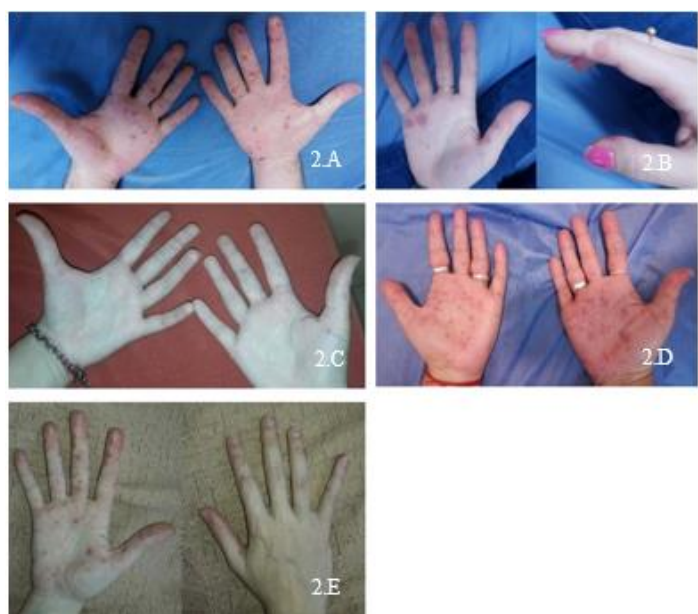

Figura 2. casos clínicos 1 al 5 (A-B-C-D-E): máculas, pápulas eritemato purpúricas, vesículas contenido seroso con halo eritematoso en palmas de ambos manos, algunas se extienden a dorso.
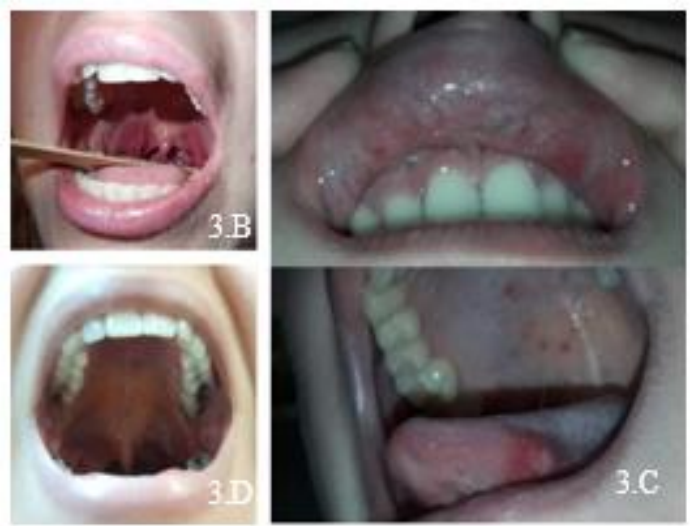

Figura 3. casos clínicos 2 al 4 (B-C-D):

Enantema faríngeo. vesículas tensas de contenido claro en mucosa yugal, y cara lateral izquierda de lengua.

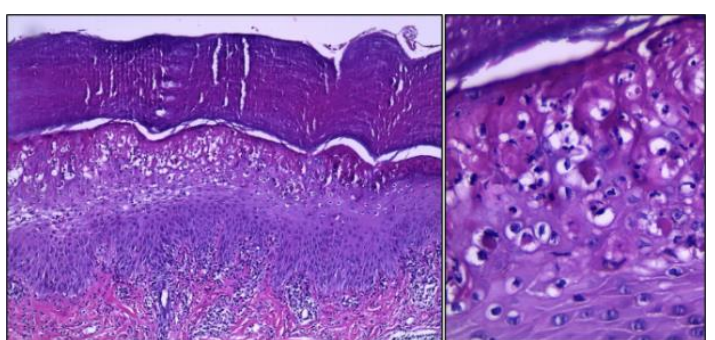

Figura 4. Epidermis con acantosis, degeneración balonizante con frecuentes disqueratinocitos necróticos. (HE;10x). A la derecha a mayor aumento disqueratinocitos en el espesor epitelial, zonas espongiosis y material proteinaceo. (HE;40x).

\section{Comentario}

La EMPB fue descrita por primera vez en 1958 por Robinson et al. durante un brote en Nueva Zelanda. Actualmente se conoce que es un exantema vírico agudo, en general autolimitado, altamente contagioso, causado por la familia
Picornaviridae ${ }^{2,3,4}$. Esta familia incluye a los Coxsackie A5, A6, A7, A9, A10, A16, B2, B3, B5, echovirus, y otros enterovirus (EV), siendo los principales agentes causales el virus Coxsackie A16 (CVA16) y enterovirus 71 (EV71) ${ }^{3,4}$. La EMPB es endémica en países de Asia, siendo más severa en China, donde predomina el EV71. Sin embargo, a partir del año 2004 se reportaron brotes epidémicos a nivel mundial incluyendo Europa y Estados Unidos, donde el CVA6 fue asociado a presentaciones atípicas predominantemente en adultos $^{1-2}$. Esta enfermedad afecta en su mayoría a niños menores de 10 años y adultos inmunocomprometidos. La presentación en adultos inmunocompetentes es infrecuente y tiene mayor prevalencia en varones ${ }^{2,3,4}$.

El ciclo de la EMPB ha sido ampliamente estudiado. Se conoce que la EMPB se asocia a cambios climáticos, con mayor prevalencia en primavera y otoño, pudiendo detectarse todo el año en regiones tropicales ${ }^{2,3}$. La transmisión es de persona a persona, siendo la principal vía fecal oral y aunque menos frecuente, puede ocurrir mediante la vía inhalatoria o contacto directo con contenido de vesículas, agua o fómites. La tasa de contagio intrafamiliar es muy alta ${ }^{1,2,3,5}$. Una vez inhalado o ingerido el virus, inicia su multiplicación en mucosa orofaríngea y tubo digestivo. La viremia ocurre a las 72 horas, lo cual implica un periodo de incubación de 3 a 6 días, y luego se disemina a la mucosa oral, manos y pies. En el séptimo día se incrementan los niveles de anticuerpos y se inicia la mejoría clínica ${ }^{2,3,5}$. Los síntomas prodrómicos son inespecíficos, pudiendo presentarse malestar general, fiebre de 1 o 2 días y odinofagia. Esta etapa es seguida de un periodo de estado de 7 a 10 días, con lesiones cutáneomucosas. Las lesiones bucales son el primer signo clínico de la enfermedad y pueden aparecer antes o simultáneamente a las lesiones de manos y pies. En mucosa oral y lengua se evidencia enantema, vesículas de 4 y $8 \mathrm{~mm}$ de diámetro, que pueden presentar un halo eritematoso circundante; estas lesiones se erosionan rápidamente, pudiendo formar úlceras de fondo amarillento - grisáceas. En esta etapa es importante tratar el dolor que puede llevar a una inadecuada ingesta $y$ deshidratación. En piel se pueden observar lesiones caracterizadas por máculas, pápulas, vesículas y ampollas distribuidas en palmas y plantas, bilateralmente, las cuales pueden evolucionar a úlceras y costras. Con menor frecuencia se pueden observar en cara, nudillos, glúteos, genitales y extremidades ${ }^{1,2,3}$. La enfermedad es contagiosa desde que presentan los síntomas iniciales hasta que desaparecen las vesículas y/o ampollas de la piel ${ }^{1}$.

En algunos casos se han descrito formas severas y complicaciones. El compromiso neurológico

Revista Methodo: Investigación Aplicada a las Ciencias Biológicas. Universidad Católica de Córdoba. Jacinto 
asociado a EV71 puede incluir meningitis aséptica, encefalitis, parálisis flácida aguda y mioclonías. En niños menores de 5 años, que corresponden a la principal población de riesgo, se observó onicomadesis asociada a CVA6 y EV71. Además, el CVA6 puede presentar compromiso mucocutáneo más extenso y fiebre elevada, e intensa artritis predominantemente en la población adulta, pudiendo requerir hospitalización. El Coxsackie B (CVB) se ha relacionado con miocarditis o cardiomiopatía, siendo el serotipo más frecuente el CVB5, al cual también se han asociado casos de compromiso del sistema nervioso central en China ${ }^{6}$

Los factores de riesgo de severidad de EMPB son temperatura corporal > a $37.5^{\circ} \mathrm{C}$, con duración > a 3 días, vómitos, neutrofilia, hiperglucemia, infección por EV 71, y los extremos etarios ${ }^{2,7,8}$.

En general el diagnóstico de la enfermedad puede realizarse con la clínica. Sin embargo, en adultos puede representar un desafío, sobre todo en aquellos sin datos epidemiológicos claros; siendo necesaria la confirmación serológica a los 15 días para evaluar la seroconversión. El aislamiento del virus tiene baja sensibilidad, pero alta especificidad $^{1,3}$. Las pruebas ELISA detectan anticuerpos IgM en un porcentaje elevado de pacientes y son pruebas económicas ${ }^{9,10}$. Actualmente el método de elección es la PCR, teniendo una especificidad y sensibilidad del $100 \%$ en LCR y $88 \%$ en suero y orina combinados ${ }^{11}$, pero con la limitación que solo puede realizarse en laboratorios de alta complejidad. Las muestras para cultivo y amplificación de ácidos nucleicos por PCR deben tomarse preferentemente de garganta y del líquido de las vesículas íntegras mediante hisopado ${ }^{1,2,3,9}$. La histopatología no es patognomónica, pero puede guiar la sospecha diagnóstica, pueden observarse vesículas intraepidérmicas, con degeneración balonizante, neutrófilos y células mononucleares.

Dentro de los diagnósticos diferenciales deben incluirse gingivoestomatitis herpética, herpangina, varicela, eritema multiforme, estomatitis aftosa, erupción medicamentosa, sífilis ${ }^{1,2,3,5}$.

Se sugiere la terapia sintomática exclusivamente ya que se considera una enfermedad benigna que se autolimita a los 7 a 10 días ${ }^{1,2,3}$. La inmunoglobulina intravenosa (IGIV) puede ser beneficiosa para la meningoencefalitis en pacientes inmunodeficientes, con defectos hereditarios o congénitos en la función de los linfocitos B, en infecciones neonatales potencialmente mortales, infecciones graves en personas con patología tumoral maligna, trasplantados de células madre hematopoyéticas, pacientes con sospecha de miocarditis viral y con enfermedad neurológica por enterovirus $71^{2,3,12}$.
En lo referido a prevención se debe identificar a pacientes con EMPB, así como reconocer signos de gravedad porque es de gran importancia ya que ayuda a disminuir la propagación, evitando así posibles epidemias. En 2015 se aprobó en China la primera vacuna contra EV 71 inactivado para prevenir enfermedad severa contra $\mathrm{EMPB}^{13}$, este es el primer paso para el desarrollo de vacunas multivalentes, siendo un desafío por los múltiples serotipos causantes de la enfermedad ${ }^{13,14,15}$. Se debe recomendar medidas de higiene como lavado de manos, desinfección de superficies y objetos de uso frecuente, evitar el contacto cercano y el uso de artículos personales con personas infectadas. La prevención es nuestra mejor herramienta como parte del tratamiento y abordaje de estos pacientes ${ }^{5,9}$. Al ser una enfermedad cosmopolita, como médicos debemos reconocer las características clínicas de esta enfermedad, vías de contagio y sus complicaciones, siendo nuestro deber hacer primar la educación para evitar los brotes y propagación, ya que la diseminación de esta puede ser peligroso para poblaciones de riesgo.

\section{Bibliografía}

1. Bennesch MA, Fernández Pardal P, Salvaneschi B. Enfermedad mano-pie-boca del adulto, emergencia del Coxsackie A6. Dermatol Arg. 2017; 23:183-187.

2. Omaña-Cepeda C, Martínez-Valverde A, Sabater-Recolons M, Jané-Salas E, MaríRoig A, López-López J. A literature review and case report of hand, foot and mouth disease in an immunocompetent adult. BMC Res Notes. 2016; 9 -165.

3. Belazarian LT, Lorenzo ME, Pearson AL, Sweeney SM, Wiss K. Virosis exantematosas. Wolff K, Goldsmith LA, Katz SI, Gilchrest BA, Paller AS, Leffel DJ, Fitzpatrick TB. Dermatología en Medicina General $8^{\circ}$ Ed. Panamericana, Buenos Aires, 2012; 2359-2362.

4. Stewart CL, Chu EY, Introcaso CE, Schaffer A, James WD. Coxsackievirus A6- Induced Hand-Foot-Mouth Disease. JAMA Dermatol. 2013? 149:1419-1421.

5. Slebioda Z, Dorocka-Bobkowska B. Hand, foot and mouth disease as an emerging public health problem: Case report of familial child-to-adult transmission. Dent Med Probl. 2018; 55: 99-104.

6. Anthony R, Andreoni BS, Andrea S, Colton MD. Coxsackievirus B5 associated with 
hand-foot-mouth disease in healthy adult. JAAD Case Reports. 2017; 3:165-168.

7. Bai JS, Hui JC, Ye C, Xiang DA, Bao SZ. The Risk Factors of Acquiring Severe Hand, Foot, and Mouth Disease: A Meta-Analysis. Hindawi Canadian Journal of Infectious Diseases and Medical Microbiology. 2018; $1-21$.

8. Li Y, Zhu R, Qian Y, Deng J. The Characteristics of Blood Glucose and WBC Counts in Peripheral Blood of Cases of Hand Foot and Mouth Disease in China: A Systematic Review. Plos One. 2012; 7: (1) e29003.

9. Repass GL, Palmer WC, Stancampiano FF. Hand, foot and mouth disease: identifying and managing an acute viral syndrome. Review. Cleveland Clinic Journal. 2014; 81: 537-543.

10. Yu N, Guo M, He SJ, Pan YX, Chen XX... Evaluation of human enterovirus 71 and coxsackievirus A16 specific immunoglobulin $\mathrm{M}$ antibodies for diagnosis of hand-foot-and-mouth disease. Virology Journal 2012; 9:12.

11. Faulkner C, Godbolt AM, Ambrosis BD, Triscott J. Hand, foot and mouth disease in an immunocompromised adult treated with aciclovir. Australasian Journal of Dermatology. 2003; 44: 203-206.
12. Pickering LK, Baker CJ, Kimberlin DW, Long SS (Eds.), Red Book: Report of the Committee on Infectious Diseases, 29th Edition. Enterovirus (Nonpoliovirus) and Parechovirus Infections (Group A and B Coxsackieviruses, Echoviruses, Numbered Enteroviruses, and Human Parechoviruses). Elk Grove Village, IL: American Academy of Pediatrics. 2012; 315-318.

13. Qun-ying M, Yiping W, Lianlian B, Miao X, Zhenglun L. EV71 vaccine, a new tool to control outbreaks of hand, foot and mouth disease (HFMD), Expert Review of Vaccines. 2016; 15: 599-606.

14. Klein MH. EV71 vaccines: a first step towards multivalent hand, foot and mouth disease vaccines. Expert Review of Vaccines. 2015; 14: 337-340.

15. Klein M, Chong P. Is a multivalent hand, foot, and mouth disease vaccine feasible? Human Vaccines \& Immunotherapeutics. 2015; 11: 2688-2704.

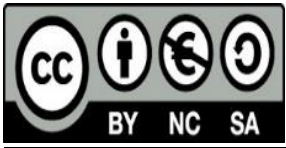

